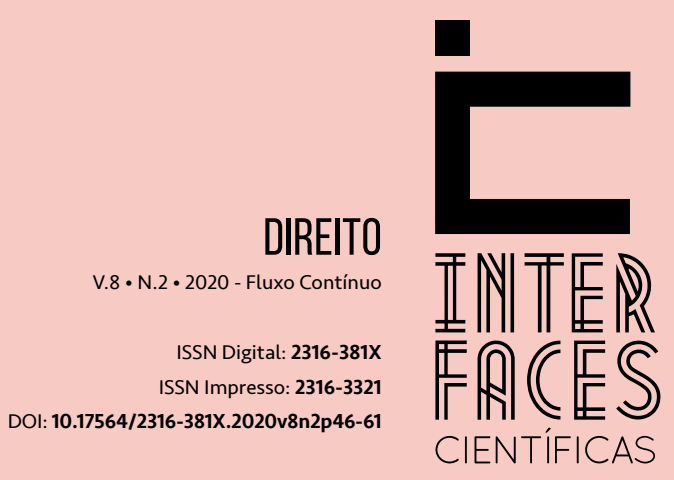

\section{ESTADO E EMPRESA DENTRO DO VIÉS CONSTITUCIONAL}

STATE AND COMPANY WITHIN CONSTITUTIONAL BIAS

ESTADO Y COMPAÑÍA DENTRO DE LA CONSTITUCIÓN

\title{
RESUMO
}

O Estado e a empresa são institutos completamente diversos, mas que possuem pontos de convergência em sua forma de atuação e objetivos, de acordo com a Carta Maior. Neste sentido, o presente trabalho tem por meta analisar a influência da concepção de eficiência de gestão que é inerente ao modelo empresarial em relação ao Estado. Por outro lado, o trabalho também pretende verificar que a empresa, muito embora tenha por objetivo o lucro, pela Carta Política, sob o viés da eficácia horizontal, deve garantir o desenvolvimento humano. Para tanto, a análise será revisional, bibliográfica e utilizará do método hipotético-dedutivo.

\section{PALAVRAS-CHAVE}

Eficiência. Eficácia Horizontal. Gestão Empresarial. Ordem Econômica. Direitos Humanos. 


\section{ABSTRACT}

The article deals with social quotas of happiness applied by fundamental rights, in the face of criticism by Roberto Campos in the 80s. It invokes the precepts of political economy for the conclusion or the Brazilian economic disaster in the face of Asian fringe liberalism. It addresses constitutional and political science aspects, having as object of criticism or current constitutional system.

\section{KEYWORDS}

Constitutional System. Search for the Right to Happiness. Economic Reality. Economic Liberalism

\section{RESUMEN}

El Estado y la empresa son institutos completamente diferentes, pero tienen puntos de convergencia en su forma de actuar y objetivos, de acuerdo con la Carta. En este sentido, este trabajo tiene como objetivo analizar la influencia de la concepción de la eficiencia de la gestión que es inherente al modelo de negocio en relación con el Estado. Por otro lado, el trabajo también tiene la intención de verificar que la empresa, aunque con fines de lucro, según la Carta Política, bajo el sesgo de eficiencia horizontal, debe garantizar el desarrollo humano. Por lo tanto, el análisis será de revisión, bibliográfico y utilizará el método hipotético-deductivo.

\section{PALABRAS CLAVE}

Eficiencia. Eficacia horizontal. Gestión empresarial. Orden económico. Derechos humanos. 


\section{INTRODUÇ̧̃̃o}

O presente trabalho objetiva iniciar um debate em torno do modelo de atuação empresarial e estatal delineado dentro da Carta Magna, sob o viés da aproximação de ambos em função da eficácia horizontal dos direitos fundamentais e da concepção de eficiência. Para tanto, o trabalho será dividido em três capítulos.

No primeiro capítulo, o trabalho analisará a concepção do Estado moderno. Além disso, verificará como tal ideário contribuiu para o modelo estatal traçado na Carta Política.

Quanto ao segundo capítulo, a pesquisa terá por objetivo verificar o modelo de atuação empresarial atualmente vigente na Carta Maior, o qual apenas será compreensível após discussão sobre as diferentes concepções de empresa que também serão levantadas em tal capítulo.

Já em relação ao terceiro capítulo, o trabalho chega ao seu cerne ao verificar o ideário empresarial e estatal traçados com a concepção de gestão empresarial sendo aplicado ao Estado e o modelo de prevalência dos Direitos Humanos, aplicando-se ao modelo empresarial. E tudo isto em conformidade com o texto da Carta Magna brasileira.

A problemática da pesquisa é a seguinte: 0 texto constitucional traz uma aproximação entre os objetivos e funções do Estado e da empresa, muito embora ambos continuem sendo instituições completamente distintas?

O objetivo geral do trabalho é o de analisar como o texto constitucional imputa o modelo de eficiência de empresarial de gestão para o Estado e a concepção de responsabilidade social para as empresas. Já os objetivos específicos são os discutir sobre as funções do Estado e das empresas, bem como iniciar um debate para um novo modelo econômico e social que possibilite efetivar a dignidade da pessoa humana.

Trata-se de pesquisa de caráter revisional, a qual utilizará do método hipotético-dedutivo e de uma análise bibliográfica para alcançar diretrizes iniciais ao problema apontado.

\section{A PERSPECTIVA ESTATAL HISTÓRICA DO ESTADO E O MODELO BRASILEIRO}

O Estado é maneira de organização social formada pela junção dos elementos povo, território e soberania. A concepção moderna de Estado surge da necessidade de organização social baseada na hierarquização centrada na figura do Estado.

Muito embora já existissem Estados baseados nas ideias de delimitação de território (mesmo que não absoluta) e da concepção de povo (cidadãos vinculados a determinado país), os conceitos de soberania e unidade nacional despertariam apenas no final do século XIV com o início das grandes navegações.

Dentro dessa ideia, pontua Dalmo de Abreu Dallari (1995, p. 59-60) sobre a ruptura do modelo feudal para o do Estado moderno:

A aspiração à antiga unidade do Estado Romano, jamais conseguida pelo Estado Medieval, iria crescer de intensidade em consequência da nova distribuição da terra. Com efeito, 
o sistema feudal, compreendendo uma estrutura econômica e social de pequenos produtores individuais, constituída de unidades familiares voltadas para a produção de subsistência, ampliou o número de proprietários, tanto dos latifundiários quanto dos que adquiriram o domínio de áreas menores. Os senhores feudais, por seu lado, já não toleravam as exigências de monarcas aventureiros e de circunstância, que impunham uma tributação indiscriminada e mantinham um estado de guerra constante, que só causavam prejuízo à vida econômica e social. Isso tudo foi despertando a consciência para a busca da unidade, que afinal se concretizaria com a afirmação de um poder soberano, no sentido de supremo, reconhecido como o mais alto de todos dentro de uma precisa delimitação territorial.

A organização da burguesia em torno da figura do monarca tinha como objetivo possibilitar segurança nos investimentos e nas explorações realizadas dentro das grandes navegações. Sem a segurança e ordenação social do Estado não há garantia de retorno nos investimentos. Da mesma forma, sem qualquer benesse, o burguês não investiria para arrecadar fundos para o Estado.

Todavia, os despertares das concepções da unidade nacional e da necessidade do Estado para segurança ali vislumbradas ainda não levariam na conscientização da soberania estatal no âmbito do Direito interno e do Direito Internacional.

Da ampliação e consolidação de tais ideários, o Tratado de Paz de Vestfália de 1648 (responsável pelo fim da Guerra dos Trinta Anos) é considerado como o momento em que os países reconheceram o conceito de unidade nacional e passaram a respeitar e a soberania uns dos outros.

Nesse sentido, muito embora já existissem os elementos de formação do Estado consolidados e a segurança concedida aos negócios do burguês com o advento do Tratado de Paz de Vestfália de 1648, ainda não havia clara limitação aos poderes do monarca. E é justamente de tal ausência que o Estado moderno é reconfigurado com o advento da revolução americana de 1776 e da revolução francesa de 1789.

Justamente fruto de ambas as revoluções burguesas em questão, o Estado moderno começa a ser governado pelo Direito. Assim, surge o Estado de Direito em contraposição ao absolutismo.

E é neste período que surge o Direito Constitucional, buscando limitar o poder soberano e garantir direitos fundamentais em seu bojo, ou seja, as Constituições podem ser compreendidas como marcos do Estado de Direito, uma vez que são textos garantistas em sua essência.

Todavia, o ideal que estava plasmado em tal momento histórico era o liberalismo, de forma que o Estado moderno ainda estava calcado especialmente na concepção de liberdade. Desta feita, muito embora também sejam lemas da revolução francesa de 1789, o Estado moderno ainda não tinha ainda grandes preocupações com os ideários de igualdade e fraternidade.

Portanto, apenas com as lutas que levaram à consagração das demais gerações ou dimensões dos Direitos Humanos (segunda e terceira) é que o Estado de Direito alcançou a concepção de Estado Democrático de Direito. Assim, preocupado com os Direitos Humanos (fundamentais ou não) de primeira, segunda e terceira geração ou dimensão.

Dentro da concepção em questão, percebe-se que o modelo de Estado moderno ao longo dos últimos séculos vem sofrendo forte influência do processo de lutas em face do poder, de forma que o modelo de organização social do Estado pauta-se pelos anseios e reivindicações sociais no campo constitucional. 
Neste sentido, o Direito Constitucional (enquanto ramo o mais importante do Direito por limitar o poder e consagrar direitos e garantias fundamentais) possui papel essencial na estrutura e organização do Estado por convergir os anseios e reivindicações sociais. Partindo do processo em questão, no qual o Estado Democrático de Direito é calcado na Constituição Federal e sua supremacia, o que influenciou diretamente o texto da Carta Magna brasileira, a qual versa no seguinte sentido em seu primeiro artigo:

Art. $1^{\circ}$ A República Federativa do Brasil, formada pela união indissolúvel dos Estados e Municípios e do Distrito Federal, constitui-se em Estado Democrático de Direito e tem como fundamentos:

I - a soberania;

II - a cidadania

III - a dignidade da pessoa humana;

IV - os valores sociais do trabalho e da livre iniciativa;

V - o pluralismo político.

Parágrafo único. Todo o poder emana do povo, que o exerce por meio de representantes eleitos ou diretamente, nos termos desta Constituição. (BRASIL, 2015, n. p.).

Assim, percebe-se que o artigo $1^{\circ}$ é enfático ao apontar o Brasil como um Estado Democrático de Direito. Além disso, vale ressaltar que o referido artigo consagra diversos valores que estão diretamente ligados aos elementos de formação do Estado (soberania e cidadania) e ideários de índole democrática (valores sociais do trabalho e da livre iniciativa, dignidade da pessoa humana, pluralismo político e o poder emanando do povo).

Já o artigo $3^{\circ}$ da Constituição trata dos objetivos fundamentais da República Federativa do Brasil. É o texto do artigo em questão:

Art. $3^{\circ}$ Constituem objetivos fundamentais da República Federativa do Brasil:

I - construir uma sociedade livre, justa e solidária;

II - garantir o desenvolvimento nacional;

III - erradicar a pobreza e a marginalização e reduzir as desigualdades sociais e regionais; IV - promover o bem de todos, sem preconceitos de origem, raça, sexo, cor, idade e quaisquer outras formas de discriminação. (BRASIL, 2015,n.p).

Da leitura atenta dos objetivos fundamentais, extraem-se valores e metas que devem nortear a atuação do Estado brasileiro. Importante destacar que tais metas não podem ser vista como imagináveis, mas, na verdade, como objetivos palpáveis tanto para o Estado quanto para a sociedade.

Por outro lado, 0 artigo $4^{\circ}$ trata sobre os princípios que regem as relações do Brasil com os demais países. Prevê o dispositivo em questão:

Art. $4^{\circ} \mathrm{A}$ República Federativa do Brasil rege-se nas suas relações internacionais pelos seguintes princípios:

I - independência nacional; 
II - prevalência dos direitos humanos;

III - autodeterminação dos povos;

IV - não-intervenção;

$V$ - igualdade entre os Estados;

$\mathrm{VI}$ - defesa da paz;

VII - solução pacífica dos conflitos;

VIII - repúdio ao terrorismo e ao racismo;

IX - cooperação entre os povos para o progresso da humanidade;

$X$ - concessão de asilo político.

Parágrafo único. A República Federativa do Brasil buscará a integração econômica, política, social e cultural dos povos da América Latina, visando à formação de uma comunidade latino-americana de nações. (BRASIL, 2015,n.p).

Após leitura do artigo $4^{\circ}$ da Carta Maior, percebe-se como o Estado brasileiro deve pautar-se sempre pelo respeito aos demais países. Assim, procura-se não-intervir nos demais, de forma que se respeite a autodeterminação dos povos e solução pacífica de qualquer conflito.

Neste sentido, o modelo de Estado Democrático de Direito adotado pelo Brasil é plural, ou seja, procura abarcar todas as gerações ou dimensões dos Direitos Humanos, bem como busca proteger as diferenças ideológicas e raciais, além de ter como meta diminuir as diferenças sociais e criar cooperação entre os países.

Da leitura em conjunto dos artigos em questão, percebe-se também o papel central atribuído ao Estado de proteção aos Direitos Humanos quando se garantem, por exemplo: dignidade da pessoa humana (artigo $1^{\circ}$ da Constituição Federal), construir uma sociedade livre, justa e solidária (artigo $3^{\circ}$ da Constituição Federal) e na prevalência dos Direitos Humanos, muito embora o Brasil pregue que não exista intervenção nos demais países (artigo $4^{\circ}$ da Constituição Federal). E isto é fruto da materialização do Estado Democrático de Direito.

Nota-se que o modelo de organização social estatal brasileiro está delineado dentro da compreensão dos artigos em questão, os quais delimitam todas as bases, objetivos e postura do Estado brasileiro perante sua população, também quanto aos demais países.

Assim, após compreender em linhas gerais a concepção de Estado Democrático de Direito no Brasil por meio dos artigos $1^{\circ}, 3^{\circ}$ e $4^{\circ}$ da Carta Maior, o presente trabalho procurará adentrar na concepção e objetivos da iniciativa privada.

\section{A CONCEPÇÃOE OS OBJETIVOS DA EMPRESA NA ÓTICA DA CARTA MAGNA DE 1988}

O conceito teórico de empresa evoluiu nas últimas décadas de forma exponencial. E muito disto é devido ao fato da busca da sujeição do modelo empresarial ao Estado Democrático de Direito, no qual se coloca a Economia como meio para concretização dos Direitos Humanos e não o contrário.

Para demonstrar como tal conceito vem evoluindo nas últimas décadas, o presente item da pesquisa pretende relatar alguns casos e como o paradigma empresarial foi alterado com seu advento. 
Dentro das ideias aqui traçadas, a concepção de empresa está ligada intrinsicamente ao conceito de responsabilidade social empresarial. E as primeiras discussões sobre tal tema surgiram em 1919, dentro do caso Dodge contra Ford, nos Estados Unidos. Antes do caso em questão, o modelo de empresa apenas era visto como uma entidade de deveria apenas dar lucro para os seus acionistas.

No caso Dodge contra Ford discutiu-se se a empresa poderia retirar o lucro dos seus acionistas para transferir para melhorias das condições de trabalho de seus funcionários. Ao final, a Ford teve seu objetivo de repasse do lucro frustrado, de forma que ficou ali caracterizado que a empresa era instituição voltada para satisfazer seus acionistas (ASHLEY, 2009).

Muito embora tal iniciativa tenha sido frustrada, as discussões sobre a responsabilidade empresarial continuaram nas décadas seguintes. Todavia, a consolidação do ideário previsto no julgado Dodge contra Ford levou Milton Friedman (1970) publicar trabalho no sentido de que a responsabilidade social empresarial estava realizada com a elaboração do lucro dentro da lei.

Contudo, com o advento do novo ciclo da globalização econômica, no final da década de 1970, tal debate alterou-se. Com tal ciclo iniciado, as formas de relações sociais do planeta foram alteradas, Saskia Sassen (2010) aponta o surgimento de dois paradigmas no período em questão: desestabilização do conceito de Estado-nação e empoderamento do setor empresarial transnacional.

Neste sentido, as empresas transnacionais passaram a buscar países com sistemas legislativos mais frágeis em busca da maximização do lucro. Com a globalização econômica seria possível manter o centro de inteligência empresarial nos países mais desenvolvidos e a operação nos países em desenvolvimento. Portanto, caso as empresas fossem vistas como instituições que apenas deveriam gerar o lucro de acordo com a lei, tal situação estaria em conformidade com o ideário empresarial.

Assim, procurando consolidar o sistema protetivo global dos Direitos Humanos, o setor empresarial começou a ser visto como responsável pela efetivação de tais Direitos em qualquer parte do globo. Josue Lafayete Petter (2008, p. 293-294) explica sobre o novo modelo de gestão empresarial:

Como o desenvolvimento não se reduz apenas ao aspecto econométrico da expressão crescimento econômico -, mas importa mesmo uma elevação do nível cultural-intelectual comunitário, e, portanto, é um processo ativo de mudança social, a redução das desigualdades regionais traz enormes benefícios para o País, especialmente se considerarmos a imensidão do território nacional. Ao contrário, a má distribuição de renda conduz a uma série de problemas sociais, a começar pelos grandes fluxos migratórios e o inchamento das grandes cidades, os quais, por sua vez, acabam por levar a outros problemas, como o sobrecarregamento, em determinadas regiões, da infraestrutura de serviços de utilidade pública - v.g., energia, comunicações, transportes - e da rede fornecedora de serviços públicos - saúde, saneamento, educação -, além do aumento da criminalidade e da violência urbana e até do crescimento da discriminação social.

E é nesta concepção que a empresa começa a ser vista como instituição que deve preocupar-se como o todo o no seu agir, ou seja, com todos os stakeholders que fazem parte da sua cadeia produtiva. Neste sentido, o agir empresarial não deve ser apenas de acordo com a lei, mas também ético.

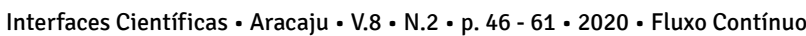


Conforme previsto no item no primeiro capítulo desta exposição, o artigo $1^{\circ}$, IV da Constituição Federal de 1988 coloca como fundamentos da República Federativa do Brasil tanto a livre iniciativa quanto os valores sociais do trabalho.

Portanto, dentro da concepção jurídica do Estado Democrático de Direito brasileiro, adota-se o capitalismo como modelo econômico. Porém, muito embora capitalista, em face da sujeição ao Estado Democrático de Direito, o capitalismo deverá respeitar os valores sociais do trabalho. Assim, resguarda-se trabalhador e empregador dentro da relação jurídica constitucional.

Mais do que isto, muito embora não estejam lado a lado no mesmo inciso, como acontece com livre iniciativa e valores sociais do trabalho, a dignidade da pessoa humana também está inserida no artigo $1^{\circ}$ da Constituição Federal, de forma que a iniciativa privada também deve valorizá-la.

Justamente dentro da concepção em questão que pontua Paulo Bonavides (2011, p. 189) sobre o tema:

Naturalmente, não se contentou a massa proletária apenas com o direito formal do voto, senão que fez dele o uso que seria lícito esperar e que mais lhe convinha: empregou-o, sem hesitação, em benefício dela mesma, ou seja, dos trabalhadores, mediante legislação de compromisso que veio amortecer o ímpeto da questão social. Com a reconciliação entre o capital e o trabalho, por via democrática, todos lucram. Lucra o trabalhador, que se vê suas reivindicações mais imediatas e prementes atendidas satisfatoriamente, numa fórmula de contenção de egoísmo e de avanço para formas moderadas do socialismo fundado sobre o consentimento. E lucram também os capitalistas, cuja sobrevivência fica afiançada no ato de sua humanização, embora despojados daqueles privilégios de exploração impune, que constituíam a índole sombria do capitalismo, nos primeiros tempos em que se implantou.

Assim, o Estado Democrático de Direito previsto na ordem constitucional não nega o lucro, mas procura compatibilizá-lo com os Direitos Humanos (fundamentais ou não). Neste sentido, a empresa (iniciativa privada) deve ser vislumbrada dentro do aspecto econômico e jurídico:

Tende-se, francamente, ao posicionar-se a empresa no universo jurídico, a privilegiar - no âmbito da regulação jurídica da Economia - o aspecto dinâmico representado pela empresa, em substituição ao traço estático que representou a propriedade, em consonância com a ideia de desmaterialização da riqueza. Ou seja, tende-se a identificar a empresa como uma atividade, vinculada à organização de uma série de fatores de conteúdo econômico para a prossecução de determinados fins (dentre eles, obviamente, o de gerar lucro). (SELEME, 2000, p. 269).

Além do artigo $1^{\circ}$, o artigo 170 da Constituição Federal procura também trazer o Estado Democrático de Direito aqui já narrado para dentro da ótica empresarial ao compatibilizar uma diversidade de institutos dentro dos princípios da ordem econômica. Versa o artigo em questão:

Art. 170. A ordem econômica, fundada na valorização do trabalho humano e na livre iniciativa, tem por fim assegurar a todos existência digna, conforme os ditames da justiça 
social, observados os seguintes princípios:

I - soberania nacional;

II - propriedade privada;

III - função social da propriedade;

IV - livre concorrência;

$V$ - defesa do consumidor;

$\mathrm{VI}$ - defesa do meio ambiente, inclusive mediante tratamento diferenciado conforme o impacto ambiental dos produtos e serviços e de seus processos de elaboração e prestação; (Redação dada pela Emenda Constitucional n 42, de 19.12.2003)

VII - redução das desigualdades regionais e sociais;

VIII - busca do pleno emprego;

IX - tratamento favorecido para as empresas de pequeno porte constituídas sob as leis brasileiras e que tenham sua sede e administração no País.

Parágrafo único. É assegurado a todos o livre exercício de qualquer atividade econômica, independentemente de autorização de órgãos públicos, salvo nos casos previstos em lei. (BRASIL, 2015, n.p).

André Ramos Tavares (2008, p. 238), comentando o artigo em questão, ressalta:

Além daqueles princípios fundamentais - livre iniciativa e valor social da iniciativa humana - enumerados em seu caput, o art. 170 das Constituição relaciona em seus nove incisos os princípios constitucionais da ordem econômica, afirmando que esta tem por fim assegurar a existência digna, conforme os ditames da justiça social, respeitados os seguintes princípios: soberania nacional, propriedade privada, função social da propriedade, livre concorrência, defesa do consumidor, defesa do meio ambiente, redução das desigualdades regionais e sociais, busca do pleno emprego e tratamento favorecido para as empresas de pequeno porte constituídas sob as leis brasileiras e que tenham sua sede e administração no país. Estes princípios perfazem um conjunto cogente de comandos normativos, devendo ser respeitados e observados por todos os "Poderes", sob pena de inconstitucionalidade do ato praticado ao arrepio de qualquer deles. Portanto, serão inadmissíveis (inválidas) perante a ordem constitucional as decisões do Poder Judiciário que afrontarem estes princípios, assim como as leis e qualquer outro ato estatal que estabelecer metas e comandos normativos que, de qualquer maneira, oponham-se ou violem tais princípios.

Portanto, da concepção do previsto no artigo em questão, a empresa deve ser eficiente na busca da gestão de seu patrimônio para aumentar o lucro, mas o modelo de eficiência ali, buscado não pode violar os Direitos Humanos (fundamentais ou não) em busca do lucro indiscriminado.

Verificado o modelo empresarial previsto dentro da ordem constitucional de 1988, o trabalho entrará no desfecho de sua análise, ou seja, procurará aprofundar-se nos pontos de convergência entre Estado e iniciativa privada no próximo item de sua exposição. 


\section{PONTOS DE CONVERGÊNCIA ENTRE ESTADO E INICIATIVA PRIVADA}

O texto constitucional brasileiro de 1988 foi alterado por meio da emenda constitucional $n^{0} 19$ de 1998, em seu artigo 37, para incluir o ideário da eficiência entre os princípios da administração pública. Versa o artigo em questão:

Art. 37. A administração pública direta e indireta de qualquer dos Poderes da União, dos Estados, do Distrito Federal e dos Municípios obedecerá aos princípios de legalidade, impessoalidade, moralidade, publicidade e eficiência [...] (Redação dada pela Emenda Constitucional $n^{0}$ 19, de 1998) [grifou-se]. (BRASIL, 2015, n.p).

Ao trazer o ideário da eficiência, de forma explícita, para dentro do texto constitucional, em especial na parte dos princípios da administração pública, o legislador buscou aproximar o Estado e sua forma de atuação do modelo gerencial empresarial, sem, contudo, descaracterizar as diferenças e peculiaridades de cada um.

Há de se destacar, inclusive, que o modelo em questão foi justamente retirado do modelo empresarial, no qual há preocupação voltada com a gestão nos recursos da melhor forma possível. Nas palavras de José Afonso da Silva (2005, p. 671-672) o princípio da eficiência deve ser visto sob o aspecto econômico, em especial:

[...] Numa idéia muito geral, eficiência significa fazer acontecer com racionalidade, o que implica em medir os custos que a satisfação das necessidades públicas importam em relação ao grau de utilidade alcançado. Assim, o princípio da eficiência, introduzido agora no art. 37 da Constituição pela EC-19/98, orienta a atividade administrativa no sentido de conseguir os melhores resultados com os meios escassos de que se dispõe e a menor custo. Rege-se, pois, pela regra da consecução do maior benefício com o menor custo possível. Portanto, o princípio da eficiência administrativa tem como conteúdo a relação meios e resultados. [...] Isso quer dizer, em suma, que a eficiência administrativa se obtém pelo melhor emprego dos recursos e meios (humanos, matérias e institucionais) para melhor satisfazer às necessidades coletivas num regime de igualdade dos usuários. Logo, o princípio da eficiência administrativa consiste na organização racional dos meios e recursos humanos, materiais e institucionais pra a prestação de serviços públicos de qualidade com razoável rapidez, consoante previsão do inciso LXXXVIII do art. $5^{\circ}$ (EC-45/2004) e em condições econômicas de igualdade dos consumidores.

Roseli Borin e Maria Priscila Soares Berro (2015, p. 90-91) também pontuam sobre a eficiência no seguinte trecho:

Sem adentrar no tema, cabe ressaltar, mais uma vez, que a inserção no texto constitucional do princípio da eficiência decorre do fato da Reforma Administrativa de 1995 ter se orientado pelo modelo da administração pública gerencial, caracterizada basicamente 
pela busca de resultados e atendimento dos anseios do cidadão-usuário.

Outrossim, é a própria sociedade que está a impor uma atuação estatal ditada pela melhor e mais racional utilização dos meios, mas que também esteja comprometida com resultados, em observância ao interesse público.

Ao elevar a eficiência à categoria de preceito constitucional, procurou-se deixar clara a necessidade de que a Administração Pública se conduza de modo a produzir serviços adequados, com maior qualidade e tendentes a cumprir satisfatoriamente seus fins legais.

Na concepção em questão, o modelo de gestão estatal deve utilizar-se das concepções empresariais de eficiência. Contudo, sem se esquecer de que o objetivo final do Estado (promoção do bem-estar social e regulação da vida em sociedade) não se pode confundir com o da empresa (lucro).

Além disso, a empresa constitucional continua com o objetivo voltado ao lucro do empresário. Todavia, além do lucro, seu cerne também está voltado na efetivação dos direitos fundamentais. Ao realizar tal ação, em momento algum, objetiva-se retirar do Estado tal incumbência, mas sim reparti-la, sem, contudo, inviabilizar a atividade do empresário.

Neste sentido, a grande ferramenta de mediação que poderá transitar no modelo capitalista como forma de conciliar os interesses do empresário (lucro) com o desenvolvimento humano será por meio da eficácia horizontal dos direitos fundamentais, a qual se deve frisar não pode ser absoluta, sob pena de descaracterizar a iniciativa privada.

Ingo Wolfgang Sarlet (2006, p. 395) pondera sobre o reconhecimento dos direitos fundamentais nas relações privadas:

Ponto de partida para o reconhecimento de uma eficácia de direitos fundamentais na esfera das relações privadas é a constatação de que, ao contrário do Estado clássico e liberal de Direito, no qual os direitos fundamentais, na condição de direitos de defesa, tinham por escopo proteger indivíduo de ingerências por parte dos poderes públicos na sua esfera pessoal e no qual, em virtude de uma preconizada separação entre Estado e sociedade, entre o público e o privado, os direitos fundamentais alcançavam sentido apenas nas relações entre os indivíduos e o Estado, no Estado social de Direito não apenas o Estado ampliou suas atividades e funções, mas também a sociedade cada vez mais participa ativamente do exercício do poder, de tal sorte que a liberdade individual não apenas carece de proteção contra os poderes públicos, mas também contra os mais fortes no âmbito da sociedade, isto é, os detentores de poder social e econômico, já que é nesta esfera que as liberdades se encontram particularmente ameaçadas.

Da compreensão da obra de Daniel Sarmento (2006), extrai-se que a eficácia horizontal terá maior incidência toda a vez que se encontrar uma assimetria fática, ou seja, quanto mais desigual o fato, maior será a incidência dos direitos fundamentais.

Porém, há de se tomar muito cuidado com tal concepção, como pontuam Diogo Basilio Vailatti e Marcelo Benacchio (2015, p. 364) ao analisar a concepção de Daniel Sarmento: 
Contudo, não se pode utilizar este conceito de forma indiscriminada. Mesmo nas relações de consumo, em que as desigualdades entre as partes costumam ser latentes, tal critério será uma regra que comporta exceções, sendo necessário utilizar da regra da proporcionalidade (adequação, necessidade e proporcionalidade em sentido estrito) para compatibilizar os direitos sociais e econômicos envolvidos.

Neste sentido, a proporcionalidade é a ferramenta que será capaz de mediar tanto os interesses privados quanto os de ordem pública, fazendo com que se construa uma ponte que interligue as novas incumbências empresariais calcadas no artigo 170 da Constituição com o objetivo de alcançar o lucro que é intrínseco a empresa.

Por meio da eficácia horizontal, a empresa deve-se aproximar do Estado como promotora dos direitos fundamentais. Todavia, muito embora próximos, a empresa ainda tem um objetivo diverso do Estado, qual seja: a busca do lucro.

Assim, não se pode esperar que a incidência dos direitos fundamentais na relação entre particulares dê-se na mesma proporção que com o Estado, mas se deve esperar que a empresa também seja uma instituição responsável por sua concretização, haja vista o disposto no artigo 170 da Constituição Federal. 0 modelo de gestão empresarial constitucional é claro neste sentido e cria tal responsabilidade para o setor empresarial.

\section{CONCLUSÃO}

O presente estudo teve como objetivo verificar como o texto constitucional brasileiro aponta pela aproximação dos objetivos e forma de atuação da empresa e do Estado quando se fala na gestão eficiente estatal e na valorização dos Direitos Humanos pelas empresas, principalmente pela eficácia horizontal e na leitura do artigo 170 da Carta Política.

Depois da investigação da concepção empresarial em seu primeiro item, a pesquisa concluiu que o modelo de atuação estatal vem evoluindo nos últimos séculos e que, tal alteração, refletiu diretamente no modelo de Estado Democrático de Direito adotado no Brasil em sua Carta Política.

No segundo item, o artigo centrou-se em verificar como a Carta Maior, em função da evolução histórica da concepção empresarial, buscou traçar a empresa como uma instituição voltada ao lucro, mas também sob a preocupação dos Direitos Humanos.

Já no terceiro item, após verificar todo o processo em questão, o trabalho voltou-se em verificar como o modelo de gestão empresarial hoje deve influenciar a atuação do Estado, em especial com o destaque dado ao tema após o advento do princípio da eficiência dentro do artigo 37 da Carta Maior. Por outro lado, calcado no artigo 170 da Carta Política e na concepção de eficácia horizontal, o item também demonstrou como a empresa deve ser uma instituição responsável pela efetivação dos Direitos Humanos.

Assim, chegou-se ao fim da pesquisa com uma resposta no sentido de que, muito embora ainda possuam diferenças, peculiaridades e algumas concepções antagônicas, empresa e Estado possuem 
objetivos e formas de atuação que em muito se aproximam pelo texto da Carta Maior, em especial na concepção de eficiência e promoção dos Direitos Humanos.

\section{REFERÊNCIAS}

ASHLEY, Patricia Almeida. A mudança histórica do conceito de responsabilidade social empresarial. In: ASHLEY, Patricia Almeida (Org.). In: Ética e responsabilidade social nos negócios. São Paulo, Saraiva: 2009. p, 43-65.

BONAVIDES, Paulo. Do estado liberal ao estado social. 10. ed. São Paulo: Editora Malheiros, 2011.

BORIN, Roseli; BERRO, Maria Priscila Soares. Breves reflexões sobre o princípio da eficiência como meio de combate a corrupção na administração pública, p. 84-108. In: DIAS, Maria Tereza Fonseca; SILVA, Lucas Gonçalves da; CALDAS, Roberto Correia da Silva Gomes (Coord.). Direito Administrativo e Gestão Pública I. Florianópolis: Funjab, 2015.

BRASIL. Constituição da República Federativa do Brasil de 1988. Brasília, DF: Senado Federal, São Paulo: Saraiva, 2015.

DALLARI, Dalmo de Abreu. Elementos de teoria geral do estado. São Paulo: Saraiva, 1995.

FRIEDMAN, Milton. The Social Responsibility of Business is to Increase its Profits. The New York Times Magazine, 1970. Disponível em: http://www.colorado.edu/studentgroups/libertarians/ issues/friedman-soc-resp-business.html. Acesso em: 30 dez. 2019.

GRAU, Roberto Eros. A ordem econômica na Constituição de 1988. 17. ed. São Paulo: Malheiros, 2015.

LIMA E SILVA, Rodrigo. Evolução histórica e desafios dos modelos de Estado de Direito, p. 449-471. In: SALGADO, Karine; SOUZA, Leonardo da Rocha de; MORAIS, José Luiz Bolzan de (Coord.). Teoria e filosofia do Direito. Florianópolis: Funjab, 2015.

MIRANDA, Jorge. Manual de direito constitucional. Tomo II. 6. ed. Coimbra: Editora Coimbra, 1996.

PETTER, Lafayete Josué. Princípios constitucionais da ordem econômica, o significado e o alcance do art. 170 da Constituição Federal. São Paulo: Revista dos Tribunais, 2008.

TAVARES, André Ramos. Direito constitucional econômico. São Paulo: Método, 2003. 
TAVARES, André Ramos. 0 que o dinheiro não compra: os limites morais do mercado. Tradução de Clóvis Marques. Rio de Janeiro: Civilização Brasileira, 2012.

SAMPAIO, José Adércio Leite. Direitos fundamentais: retórica e historicidade. Belo Horizonte: Del Rey, 2004.

SARLET, Ingo Wolfgang. A eficácia dos direitos fundamentais. 6. ed. Porto Alegre: Livraria do Advogado, 2006.

SARMENTO, Daniel. Direitos fundamentais e relações privadas. Rio de Janeiro: Lumen Juris, 2006. SASSEN, Saskia. Sociologia da globalização. Tradução Ronaldo Cataldo Costa. Porto Alegre: Artmed, 2010.

SELEME, Sérgio. Contrato e empresa: notas mínimas a partir da obra de Enzo Roppo. In: FACHIN, Luiz Edson (Org.). Repensando fundamentos do direito civil brasileiro contemporâneo. Rio de Janeiro: Renovar, 2000.

SILVA, Jose Afonso da. Curso de direito constitucional positivo. 25. ed. São Paulo: Malheiros, 2005.

SILVA, Virgílio Afonso da. Os direitos fundamentais nas relações entre particulares. São Paulo: Malheiros, 2005.

SILVEIRA, Vladmir Oliveira; ROCASOLANO, Maria Mendez. Os direitos humanos: conceitos, significados e funções. São Paulo: Saraiva, 2010.

SROUR, Robert Henry. Poder, cultura e ética nas organizações. $8^{a}$ edição. Rio de Janeiro: Campus, 1998.

SROUR, Robert Henry. Ética empresarial: a gestão da reputação. 2. ed. Rio de Janeiro: Elsevier, 2003.

VAILATTI, Diogo Basilio; BENACCHIO, Marcelo. A eficácia dos direitos fundamentais e a proteção do consumidor insculpida na ordem econômica: uma análise entre o absolutismo e o relativismo da tutela constitucional, p. 343-370. In: STRAPAZZON, Carlos Luiz; BELLINETTI, Luiz Fernando; COUTINHO, Sérgio Mendes Botrel (Coord.). Eficácia dos direitos fundamentais nas relações do trabalho, sociais e empresariais. Florianópolis: Funjab, 2015.

VAZ, Paulo Junio Pereira. Direito Internacional dos Direitos Humanos e sua influência na política dos Estados com vistas à proteção de grupos vulneráveis, p. 194-215. In: VERONESE, Alexandre; SOARES, Fabiana de Menezes; SILVEIRA, Vladmir Oliveira da (Coord.). Direitos Humanos e efetividade: fundamentação e processos participativos. Florianópolis: Funjab, 2015. 
ZOLO, Danilo; COSTA, Pietro. 0 estado de direito: história, teoria, crítica. Tradução de Carlo Alberto Dastoli. São Paulo: Martins Fontes, 2006. 
1 Doutorando em Direito pela Pontifícia Universidade Católica de São Paulo. Mestre em Direito pela Universidade Nove de Julho. Especialista em Direito Tributário. Procurador do Município de Diadema. Palestrante e conferencista. Professor universitário e em cursos preparatórios para $\mathrm{OAB}$ e concurso.

E-mail: diogo_bv23@hotmail.com benamarcelo@gmail.com

2 Doutor em Direito pela Pontifícia Universidade Católica de São Paulo (2005). Professor permanente do Mestrado em Direito e da Graduação da Universidade Nove de JulhoUNINOVE. Professor Convidado da Pós Graduação lato sensu da PUC/COGEAE e da Escola Paulista da Magistratura. Professor Titular de Direito Civil da Faculdade de Direito de São Bernardo do Campo. Juiz de Direito em São Paulo E-mail: benamarcelo@gmail.com

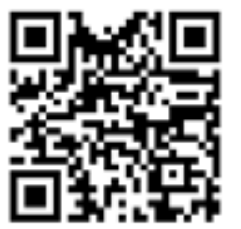

A autenticidade desse artigo pode ser conferida no site https://periodicos. set.edu.br

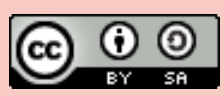

Este artigo é licenciado na modalidade acesso abertosob a Atribuição-Compartilhalgual CC BY-SA

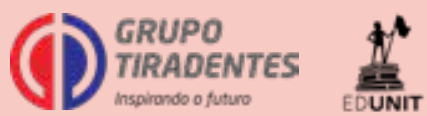

